\title{
Factor Analysis and Principal Component Analysis Concerning to Occupational Stress among Executive Officers of Nepal
}

\author{
R Kayastha $^{1, *}$, V Krishna Murthy ${ }^{2}$, P R Adhikary ${ }^{3}$ \\ ${ }^{1}$ Department of Natural Sciences, School of Science, Kathmandu University, Nepal \\ ${ }^{2}$ Department of Biotechnology, PES University Bangalore, India \\ ${ }^{3}$ Kathmandu College of Management, Kathmandu, Nepal
}

Copyright (C) 2015 Horizon Research Publishing All rights reserved.

\begin{abstract}
The purpose of this paper was to extend the existing body of knowledge on the occupational stress index among executive officers into the context of governmental and non-governmental organizations of Nepal, as limited research has been conducted with respect to this field in Nepal. A conceptual framework was developed to study the occupational stress index among executive officers in the governmental and nongovernmental sectors in Nepal. Occupational stress index questionnaire was used to collect data. The overall response rate from the employees of governmental organizations and nongovernmental organizations were encouraging. The statistical approaches used and analysis done brought out many finer aspects and the realistic picture of the stress felt by the employees. The stressors, the different types of stress and its role, the effects on the individual and the organization, the natural effect, the possible stresses including the stressors have a direct bearing on executive officers have been investigated through this battery of statistical methods attempted by Factor analysis. The study also has revealed association of some of the stressors as independent variables and one of them being considered as a dependent variable.
\end{abstract}

Keywords Occupational Stress, Occupational Stress Index, Factor Analysis, Principal Components Analysis, Reliability Statistics, Eigen Values, Communality

\section{Introduction}

In a day to day life stress is deadlines, frustrations, and demands. Stress has become a way of life for many people. Stress isn't always unpleasant. In small doses, it will bring to perform under pressure and motivate to do best. But when persistently running in emergency manner, the mind and body pay the cost.

Stress is experienced when a person believes that demand is exceeding capacity to cope. The reaction is experienced when a person finds it difficult to manage the pressures contingent upon them. A stress reaction is an individual response and it may make up stress for one individual and may not be stressful for another; in the same way the type and severity of stress response varies from individual to individual

Occupation related stress among working people is drastically increasing worldwide. Stress at work place has become an integral part of everyday life and is referred as 'worldwide epidemic' by the World Health Organization. In the United States of America, nearly $25 \%$ of the working population suffers from work related stress. The figures for Nepal are not readily obtainable but there is no doubt that occupational stress affects a significant number of executive officers and costs heavy financial losses, human sufferings and mental illness [1]. In the UK Smith A, et al were investigating the scale and severity of occupational stress in current research revealed that $20 \%$ of the working people were suffering high or extremely high level of stress at work [2].

Many studies about occupational stress were accompanied using different samples, such as a stepwise multivariate analysis in UK [3] with 547 males and females general practitioners and 449 consultant doctors in Scotland health science [4], 440 Managers in multinational companies of Malaysia [5], 335 Greek junior hospital doctors in Greater Athens area [6], 461 nurses recruited from the public health and educational system in the Federal District of Brazil [7], and 23 nursing teams [8]. Findings from these studies reported that the ability of employees to cope with physiological stress i.e., the working conditions, then workloads, physical health and working hours and psychological stress i.e., pertaining at work, support the condition of their mental health and positive thinking had raised job satisfaction in the workplace.

Numerous studies have been found that job stress influences the employees' job satisfaction and their overall 
performance in their work. It is because most of the organizations now demand more for the better job outcomes. In fact, modern time has been known as the age of anxiety and stress [9]. The stress will be influenced by a number of stressors by itself. Nevertheless, Beehr and Newman had defined stress as a time which will force a person's behavior to deviate from normal functioning due to the change i.e. enhance or disrupt in psychological or physiological conditions and both [10]. From the definition of stress we come to conclude that it is really essential for an individual to recognize the stresses they are facing in their career.

The role of the management organization is one of the features that affect work-related stress among workers [11]. The meaning of role stress is anything about an organizational role that produces adverse consequences for an individual [12].

Family and work are inter-related and inter-dependent to the extent that experiences in one area affect the quality of life in the other area [13]. Lasky contented that, demands associated with family and finances can be a major source of 'extra-organizational' stress that can pressure work-place even more complicated [14]. According to Russo \& Vitaliano, the occurrence of stressors in the workplace either immediately following period of chronic stress at home, in conjunction with other major life stressors, is probably to have a marked influence on outcome [15].

Several studies have highlighted the deleterious consequences of high workloads or work overload. According to Wilkes work overloads and time constraints were significant contributors to work stress among community nurses [16]. Workload stress can be well-defined as reluctance to come to work due to the feeling of constant pressure (i.e. no effort is enough) escorted by the general psychological, physiological, and behavioral stress symptoms. Al-Aameri has stated in his studies that one of the six factors of occupational stress is pressure originating from workload [17].

Rapid change in global scene is increasing the pressure of workforce to perform for maximum output and enhance competitiveness. Indeed, to perform better in their job, it is entreated for the workers to perform multiple tasks in the workplace to keep alongside each other of changing technologies [18]. The final results of this pressure have been found as one of the important factors influencing job stress in their work [19]. A study in United Kingdom indicated that the majority of the workers were unhappy with the current culture where they were required to work during extended hours and cope with large workloads while simultaneously meeting production targets and limitation of time [20].

The present research article is conceded out the factor analysis and principal component analysis of occupational stress among employees working as executives in an organization to investigate following aspects:

(1) Identifying the factors and causing stress being experienced by executive officers working in Nepal;

(2) Determining different stresses and their significance.

\section{Factor Analysis Model}

A theorem which asserts that the correlation between two variables is the sum of the products of their factor loadings over $k$ orthogonal common factors. Letting $p_{\text {im }}$ represent the pattern coefficient for variable $\mathrm{i}$ on factor $m$, and $p_{j m}$ be the pattern coefficient for variable $j$ on factor $m$, then

$$
r_{i j}=\sum_{m=1}^{k} p_{i m} p_{j m}
$$

More generally, the correlation matrix (with communalities in the main diagonal) is equal to the pattern matrix post multiplied by its transpose.

Or

$$
(\boldsymbol{R}-\boldsymbol{U})=\boldsymbol{F} \boldsymbol{F}^{\prime}
$$

$$
\boldsymbol{R}=\boldsymbol{F} \boldsymbol{F}^{\prime}+\boldsymbol{U}
$$

where $\mathbf{R}$ is correlation matrix, $\mathbf{U}$ is a diagonal matrix of uniquenesses, $\mathbf{F}$ is the pattern matrix and $\mathbf{F}^{\prime}$ is the transpose of $\mathbf{F}$.

Factor analysis Model is a linear combination of underlying factors. The covariation among the variables is termed as a small number of common factors plus a unique factor for each variable [28].

If the variables are standardized, the factor model regarding occupational stress may be represented as:

$$
X_{i}=A_{i 1} F_{1}+A_{i 2} F_{2}+\ldots \ldots \ldots+A_{i m} F_{m}+V_{i} U_{i}
$$

where

$X_{i}=i$ th standardized variable

$A_{i j}=$ standardized multiple regression coefficient of variable $i$ on common stress factor $j$

$F=$ common stress factor

$V_{i}=$ standardized regression coefficient of variable $i$ on unique stress factor $i$

$U_{i}=$ the unique stress factor for variable $i$

$m=$ number of common stress factors

The unique occupational stress factors are uncorrelated with each other and with the common stress factors.

The common occupational stress factors themselves can be expressed as linear combinations of the observed variables.

$$
\mathrm{F}_{i}=\mathrm{W}_{i 1} \mathrm{X}_{1}+\mathrm{W}_{i 2} \mathrm{X}_{2}+\mathrm{W}_{i 3} \mathrm{X}_{3}+\ldots+\mathrm{W}_{i k} \mathrm{X}_{k}
$$

where

$F_{i}=$ estimate of $i$ th factor

$W_{i}=$ weight or factor score coefficient

$k=$ number of variables

\section{Materials and Methods}

In 1982, occupational Stress Index Questionnaire was developed to capture the specific sources of job stress in India. There were a number of measures of job stress already in existence which could have potentially been used to assess job stress among executive officers, such as the Occupational Stress Indicator [29] which was designed for 
managerial and professional staff or the Health Professionals Stress Inventory [30] which was developed to compare the sources of stress across a variety of health professionals in the USA. However, these questionnaires were not sufficiently sensitive to capture the unique and complex working lives of mangers or the executive officers and so they did not depict the specific sources of job stress experienced in Nepal.

A sample for this study is executives who are working in, Government officers, other public institutions and, private institutions engaged in different fields and are situated in different parts of Nepal. A random sampling technique was done for selection of respondents for this survey, and to record the responses about occupational stress. A total of more than 800 questionnaires were distributed to the employees in executive position, out of which 600 questionnaires were returned. Only 440 get back questionnaires were found with required information and were completely usable.

The questionnaires were considered to measure levels of occupational stress among Executives officers of Nepal. The level of stress was measured by Occupational Stress Questionnaire (OSI) in the Indian context [31]. The questionnaire is comprised of 46 statements with five alternative responses. Responses were found on a summated rating scale format ranging from "strongly agree" to "strongly disagree". Total stress score on this scale is reflected for the assessment of occupational stress. Higher scores indicated higher professed occupational stress or more the score on this scale indicates more stress. This scale comprised of twelve dimensions. Each of job stressors was based on a five-point Likert Scale in which 1 indicated "strongly disagree", 2 indicated "disagree", 3 indicated "neutral", 4 indicated "agree" and 5 indicated "strongly agree". Out of the 46 items 28 are true keyed and 18 are false keyed.

\section{Results and Analysis}

Occupational stress index was subjected to the principal component analysis using varimax rotations as there were grounds for supposing that the factors might correlate. Factors were to be considered if they had an eigenvalue over 1 , and individual sources were included if they had a loading of 0.4. This resulted in four occupational stress factors. Details of the factor loadings are depicted in table 1. The occupational stress was subjected to principal component analysis using both varimax rotations; but produced the same factor structures. The factor analysis of the core items confirmed the occupational stress factors of occupational stress index. The factor loadings are detailed in table 1 .

Factor analysis is a method of data reduction. It seeks to discover underlying unobservable and latent variables that are reflected in the observed variables. The purpose of factor analysis is to eliminate simple pattern of relationships existing among the variables. In addition to this, it tries to find out if the observed variables can be explained largely or entirely in terms of a much smaller number of variables which it name as factors. We could usefully ask about the number of dimensions on which the ratings differ.

In order to precisely capture the respondent's view among the EOs of Nepal, reliability analysis is carried out. The Reliability Statistics informs us about the value of the coefficient of Cronbach alpha for the research scale $0.822=82.2 \%$. Of this is over the percent of $80 \%$, and then it is an extra good value for the internal consequence of the conceptual construction of the investigated scale [32]. If we continue with the release of units, or with the standardized value of the variables, then the coefficient of Cronbach alpha will slightly increase the value of $\alpha=0.824$. This means that when we increase the number of the items, then Cronbach $\alpha$ will take the value of 0.824 .

The Scale Statistics gives the scores that are related to the scale's entirety, which presents a mean of the class of 131.07 and a standard deviation of the class of 15.45 units.

The mean along with standard deviation of different variables were [33]-[38] and promoting occupational stress among the EOs of Nepal as "I bear the great responsibility for the progress and prosperity of this organization" has scored the highest mean. Whereas EO's view on the factor close the available information relating to my job-role, contradictory instructions, adjustment of work, responsibility and future of a number of employees, work with persons, assignments of work, salary, work under tense circumstances, excessive work load, political pressures, colleagues and subordinates as it scored highest standard deviation.

Considering the factors promoting occupational stress has been of a major interest for EOs of Nepal. The study indicates that there are multiple sources of occupation stress like role overload, role ambiguity, role conflict, unreasonable group and political pressures, responsibility for person, under participation, powerlessness, poor peer relation, intrinsic impoverishment, low status, strenuous working conditions, and unprofitability. 
Table 1. Principal components and associate variable

\begin{tabular}{|c|c|c|c|}
\hline Factor & No & Statement & $\begin{array}{l}\text { Factor } \\
\text { Loading }\end{array}$ \\
\hline \multirow{5}{*}{ F1 } & 18 & My co-operation is frequently sought in solving the administrative or industrial problem at higher level & 0.653 \\
\hline & 19 & My suggestions regarding the training programs of the employees are given due significance & 0.63 \\
\hline & 31 & My colleague do co-operate with me voluntarily in solving administrative and industrial problems & 0.562 \\
\hline & 30 & My opinions are sought in framing important policies of the Organization/ Department & 0.558 \\
\hline & 40 & My opinion is sought in changing or modifying the working system instruments and conditions & 0.511 \\
\hline \multirow{7}{*}{$\mathrm{F} 2$} & 2 & The available information relating to my job-role and its outcome are vague and insufficient. & 0.595 \\
\hline & 42 & My suggestions and co-operation are not sought in solving even those problems for which I am quite competent & 0.569 \\
\hline & 21 & I get ample opportunity to utilize my abilities and experience independently & 0.557 \\
\hline & 35 & I often feel that this job has made my life cumbersome & 0.498 \\
\hline & 37 & It is not clear that what type of work and behavior my higher authorities and colleagues expect from me & 0.497 \\
\hline & 34 & My higher authorities do not give due significance to my post and work & 0.496 \\
\hline & 27 & I am not provided with clear instructions and sufficient facilities regarding the new assignments trusted to me & 0.478 \\
\hline \multirow{6}{*}{ F3 } & 46 & I am unable to carry out my assignment to my satisfaction on account of excessive load of work and lack of time & 0.66 \\
\hline & 26 & $\begin{array}{l}\text { I am unable to perform my duties smoothly owing to uncertainty and ambiguity of the scope of my Jurisdiction } \\
\text { and Authorities }\end{array}$ & 0.656 \\
\hline & 36 & Being too busy with official work I am not able to devote sufficient time to my domestic and personal problems & 0.652 \\
\hline & 25 & I have to dispose of my work hurriedly owing to excessive work load & 0.594 \\
\hline & 13 & Owing to excessive work load I have to manage with insufficient number of employees and resources & 0.58 \\
\hline & 12 & I do my work under tense circumstances & 0.482 \\
\hline \multirow{5}{*}{ F4 } & 17 & I am responsible for the future of a number of employees & 0.6 \\
\hline & 1 & I have to do a lot of work in this job & 0.572 \\
\hline & 5 & The responsibility for the efficiency and productivity of many employees is thrust upon me & 0.521 \\
\hline & 29 & I bear the great responsibility for the progress and prosperity of this organization & 0.509 \\
\hline & 28 & In order to maintain group-conformity sometimes I have to do/produce more than the usual & 0.509 \\
\hline \multirow{5}{*}{ F5 } & 11 & I get less salary in comparison to the quantum of my labor / work & 0.632 \\
\hline & 22 & This job has enhanced my social status & 0.552 \\
\hline & 33 & I get ample opportunity to develop my aptitude and proficiency and properly & 0.516 \\
\hline & 43 & Working conditions are satisfactory here from the point of view of our welfare and convenience & 0.497 \\
\hline & 9 & My assignments are of monotonous nature & 0.437 \\
\hline \multirow{3}{*}{ F6 } & 7 & My decisions and instructions concerning distribution of assignments among employees are properly followed & 0.667 \\
\hline & 6 & Most of the suggestions are heeded and implemented here & 0.59 \\
\hline & 10 & Higher authorities do care for my self-respect & 0.562 \\
\hline \multirow{4}{*}{ F7 } & 4 & $\begin{array}{l}\text { Sometimes it becomes complied problem for me to make adjustment between political group pressures and } \\
\text { formal rules and instructions }\end{array}$ & 0.625 \\
\hline & 16 & I have to do some work unwillingly owing to certain group / political pressures & 0.613 \\
\hline & 3 & My different officers often give contradictory instructions regarding my work & 0.558 \\
\hline & 39 & $\begin{array}{l}\text { I am compelled to violate the formal and administrative procedure and policies owing to group / political } \\
\text { pressures }\end{array}$ & 0.538 \\
\hline \multirow{4}{*}{ F8 } & 41 & $\begin{array}{l}\text { There exists sufficient mutual co-operation and team-spirit among the employees of this Organization / } \\
\text { Department }\end{array}$ & 0.637 \\
\hline & 20 & Some of my colleagues and subordinates try to defame and malign me as unsuccessful & 0.613 \\
\hline & 14 & The objective of my work role are quite and adequately planned & 0.601 \\
\hline & 32 & My colleagues do co-operate with me voluntarily in solving administrative and industrial problems & 0.558 \\
\hline \multirow{3}{*}{ F9 } & 24 & Some of my assignments are quite risky and complicated & 0.61 \\
\hline & 8 & I have to work with persons whom I like & 0.567 \\
\hline & 44 & I have to do such work as ought to be done by others & 0.565 \\
\hline \multirow[b]{2}{*}{ F10 } & 38 & Employees attach due importance to the official instructions and formal working procedures & 0.497 \\
\hline & 45 & $\begin{array}{l}\text { It becomes difficult to implement all of a sudden the new dealing procedures and policies in place of those } \\
\text { already in practice }\end{array}$ & 0.439 \\
\hline F11 & 23 & I am seldom rewarded for hard labor and efficient performance & 0.673 \\
\hline F12 & 15 & Officials do not interfere with my jurisdiction and working methods & 0.524 \\
\hline
\end{tabular}


The exploratory factor analysis was applied in order to identify the various factors promoting stress of the EOs of Nepal. Principal Component analysis method was applied for extracting factors and orthogonal rotation with varimax was employed. The latent root criterion was applied for extraction of factors, Eigen values greater than one or only the factors having latent roots were considered significant; all other factors with latent roots less than one were to be considered insignificant and hence discarded. The extracted factors along with twelve factors each having eigen value exceeding one for occupational stress factors among the EOs of Nepal. Eigen values for twelve factors were 8.078, 4.265, $1.996,1.824,1.554,1.373,1.286,1.257,1.187,1.109,1.069$, and 1.011 respectively. The index for the present solution accounted for $56.54 \%$ of the total variations for the factor promoting stress. It is a good extraction because we are able to economise on the number of choice factors (from 46 to 12 underlying factors), a loss of $46.43 \%$ information content for choice of variables. The percentages of variance are explained by one to twelve factors are: $17.56,9.271,4.34$, $3.966,3.378,2.985,2.795,2.732,2.581,2.41,2.324$, and 2.199 respectively. Large communalities designate that a large number of variance was accounted for by the factor solutions. The factor analysis from varimax rotated results for motivational factors indicates that after twelve factors are extracted the retained communality is: 0.653 for variable1, 0.511 for variable $2,0.558$ for variable 3 and so on. It means that approximately $56.54 \%$ of the variance of variable 1 was being captured by extracted factors together. Communality is the proportion of the variance in any one of the original variable which that was captured by the extracted factors [39].

The principal components with rotated components and the corresponding correlated values are depicted. The numbers depict the percentage association with the factor provides the initial eigen value, percentage of variance and cummanalities percentage. The statement associating factors and the factor loading is depicted in table 2 where in the principal component with variable is presented. The factors and the summary orientation that has its own role in causing stress are presented according to the central meaning of statements. The stressors thus summarized relate to a few factors that are:

i) Upkeep 'my' honor-"Me" centric feel good, ii) Interaction with others, iii) Unfavorable personal factor, iv) Enhanced responsibility, v) Personal feel good factors, vi)Enhance self-esteem, vii) Ambiguity generations, viii) Cooperation from workers, ix) Compulsions, $\mathrm{x}$ ) Change in different effect, xi) Unreasonable, and xii) Independence.

Since the Kaiser-Meyer-Olkin Measure of Sampling Adequacy was found to be 0.866 and which falls into the range of being between 0.8 and 0.9 , we should be confident that the factor analysis is appropriate for these data. A highly significant of Bartlett's test is appropriate for factor analysis.

The scree plot is shown in figure 1 with a thunderbolt indicating the point of inflexion on the curve and proceedings to a graphic representation of eigenvalues and conducts us to the determination of the number of the essential factorial axes. The above graph represents a distinguished breakdown up to twelve factors, whereas after the twelve factors an almost linear part of the eigenvalue curve follows. Thus, we can make under this consideration of the eigenvalues, which are over one for all the twelve factors.

Table 2. Combination of the leading stressors

\begin{tabular}{|c|c|c|}
\hline Factors & Statement & $\begin{array}{c}\text { Summary of statements } \\
\text { (leading stress) }\end{array}$ \\
\hline F1 & $18,19,30,31,40$ & $\begin{array}{c}\text { Upkeep 'my' honor-"Me" } \\
\text { centric feel good }\end{array}$ \\
\hline F2 & $2,21,27,34,35,37,42$ & Interaction with others \\
\hline F3 & $12,13,25,26,36,46$ & Unfavorable personal factor \\
\hline F4 & $1,5,17,28,29$ & Enhanced responsibility \\
\hline F5 & $9,11,22,33,43$ & Personal feel good factors \\
\hline F6 & $6,7,10$ & Enhance self esteem \\
\hline F7 & $3,4,16,39$ & Ambiguity generations \\
\hline F8 & $14,20,32,41$ & Cooperation from workers \\
\hline F9 & $8,24,44$ & Compulsions \\
\hline F10 & 28,45 & Change in different effect \\
\hline F11 & 23 & Unreasonable \\
\hline F12 & 15 & Independence \\
\hline
\end{tabular}

Scree Plot

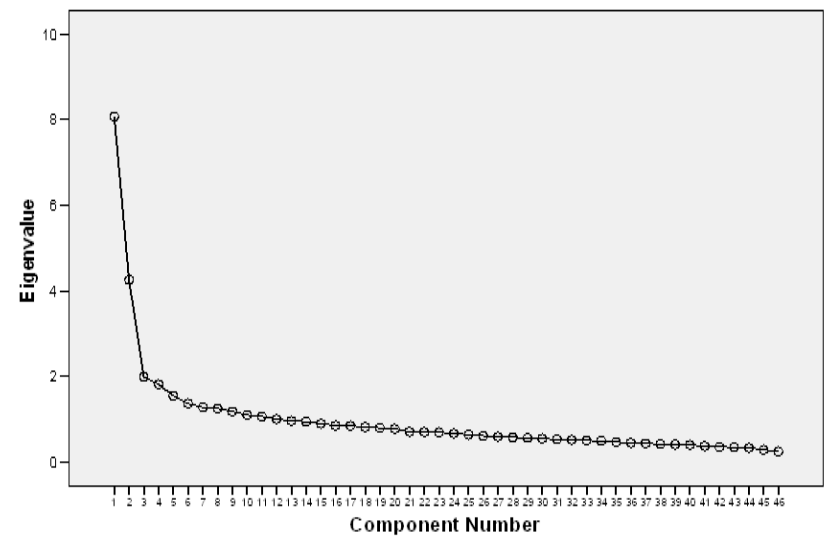

Figure 1. Scree Plot

\section{Conclusions}

Stress is a significantly growing concern in many workplaces today but very little research has been done on stress among executive officers of Nepal. The objective of this paper was to develop different type of stressors in executive officers field personnel are exposed to while on the contribution of variables such as Role overload, Role ambiguity, Role conflict, Political, Responsibility, Under participation, Powerlessness, Poor peer relation, Intrinsic Impoverishment, Low status, Strenuous working condition, Unprofitability is doing to manage or mitigate the effects of negative long-term stress among executive officers of Nepal. 
There is an obvious need for improving organizational affects by using newly available technology but it may take time. Focus on how the organizations can improve and also the executive officers can be made more efficient by dealing with occupational stress seems to have been neglected to some degree.

During this research, no earlier reports that investigated specific stress factors and comparison made between different executive officers of Nepal were found. Therefore, to answer what stressors existed among them, quantitative questionnaire survey method was adopted and questionnaires were distributed among officers and twelve potential stress factors were rated by the executive officers.

For this purpose factor analysis treatment and analysis was done to infer many finer aspects. The stress and its implications besides the effects can cause on the serious problem on their health. The stressors, the different types of stress and its role, the effects on the individual and the organization, the natural effect, the possible stresses including the stressors has a direct bearing and its role on executive officers have been investigated through these battery of factor analysis method.

The principal component analysis by using varimax rotations method resulted in four occupational stress factors. The factor analysis of the core items confirmed the occupational stress factors of occupational stress index.

The Reliability Statistics carried out that the coefficient of Cronbach alpha for the research scale $0.822=82.2 \%$ which had bearing a good internal consequence of the construction of the investigated scale consistency for this research.

The Scale Statistics gave the scores that were related to the scale's entirety, of the highest mean of different variables were and promoting occupational stress among the EOs of Nepal as "I bear the great responsibility for the progress and prosperity of this organization" whereas EO's view on the factor close to the available information relating to my job-role, contradictory instructions, adjustment of work, responsibility and future of a number of employees, work with persons, assignments of work, salary, work under tense circumstances, excessive work load, political pressures, colleagues and subordinates were attained highest standard deviation.

The study designated that the multiple sources of promoting occupation stress for EOs of Nepal like role overload, role ambiguity, role conflict, unreasonable group and political pressures, responsibility for person, under participation, powerlessness, poor peer relation, intrinsic impoverishment, low status, strenuous working conditions, and unprofitability.

Further from the principal components with rotated components and the corresponding correlated values in association with the factors the initial eigen value, percentage of variance and cummanalities percentage were found the combination of the leading stressors. The factors and the summary orientation that has its own role in causing stress were presented according to the central meaning of statements. The leading stressors thus summarized relate to a few factors found were table 2 .

The importance of this study cannot be exaggerated for the long-term survival of any organizations planning to build a healthy working environment while reducing the risk of work-related diseases and accidents. The influence of variables such as role overload, role ambiguity, role conflict, unreasonable group or political pressure, responsibility, under participation, powerlessness, poor peer relation, intrinsic impoverishment, low status, strenuous working condition, unprofitability to level of stress has its own significance. The findings of this study thus might help, in applying a healthy working environment. Cautious and well-planned application strategies in work, role clarity, and training and development can provide a fruitful result to the employees and organizations both.

The current analysis adds to the literature on occupation stress and prevention of occupation stress especially in the Nepalese context. Generally, these executives faced with the sources of stress across all organizations. The study revealed that executive officers of Nepal were suffering from stress and there were significant differences obtained in occupational stress in executive officers of Nepal basically with their stressors i) Upkeep 'my' honor-"Me" centric feel good, ii) Interaction with others, iii) Unfavorable personal factor, iv) Enhanced responsibility, v) Personal feel good factors, vi)Enhance self-esteem, vii) Ambiguity generations, viii) Cooperation from workers, ix) Compulsions, $\mathrm{x}$ ) Change in different effect, xi) Unreasonable, and xii) Independence.

\section{REFERENCES}

[1] R. . AbuAlRub, "Job stress, job performance and social sup-port among hospital nurses,” J. Nurs. Scholarsh., 2004.

[2] A. Baum, N. E Grunberg, and J. E Singer, "The use of psychological and neuroendocrinological measurements in the study of stress," in Health psychology, 1st ed., 1982, pp. 217-236.

[3] S. R. Snelgrove, "Occupational stress and job satisfaction: A comparative study of health visitors, districts nurses and community psychiatric nurses," J. Nurs. Manag., vol. 6, no. 2, pp. 97-104., 1998.

[4] V. Swanson, K. Power, and R. Simpson, "A comparison of stress and job satisfaction in female and male GPs and consultants," Stress Med., vol. 1, no. 12, pp. 17-26., 1998.

[5] A. T. Manshor, R. Fontaine, and C. S. Choy, "Occupational Stress among Managers: A Malaysian Survey,” J. Manag. Psychol., vol. 18, no. 6, pp. 622-628, 2003.

[6] A. S. G. Antoniou, M. J. Davidson, and C. L. Cooper, "Occupational stress, job satisfaction and health state in male and female junior hospital doctors in Greece," J. Manag. Psychol., vol. 18, no. 8, pp. 592-621., 2003.

[7] J. M. R. Stacciarini, "Occupational stress and constructive thinking: Health and job satisfaction.," J. Adv. Nursing,, vol. 5, no. 46, pp. 480-487., 2003. 
[8] J. Quoidah and M. Hansenne, "The impact of trait emotional intelligence on nursing team performance and cohesiveness 25(1), 23-29.," J. Prof. Nurs., vol. 1, no. 25, pp. 23-29., 2009.

[9] J. C. Coleman, Abnormal Psychology and Modern Life. Bombay: (Indian reprint), Taraporewalla, 1976.

[10] T. A. Beehr and J. E. Newman, "Job stress, employee health and organisational effectiveness. A facet analysis, model and literature review.," Pers. Psychol., no. 31, pp. 665-669, 1978.

[11] G. A. Alexandros-Stamatios, J. D. Matilyn, and L. C. Cary, "Occupational Stress, Job satisfaction, and health state in male and female junior hospital doctors in Greece," J. Manag. Psychol., vol. 18, no. 6, pp. 592-621, 2003.

[12] R. L. Kahn and R. P. Quinn, Role stress: A framework for analysis. New York: Wiley, 1970.

[13] S. Sarantakos, Modern Families, South Yarra. MacMillan Education Australis Pty Ltd., 1996.

[14] R. G. Lasky, Occupational stress: a disability management perspective. 1995 , pp. 370-409.

[15] J. Russo and P. Vitaliano, "Life events as correlates of burden in spouse caregivers of persons with Alzheimers disease,” Exp. Ageing Res., vol. 21, pp. 273-294, 1995.

[16] L. Wilkes, B. Beale, E. Hall, E. Rees, B. Watts, and C. Denne, "Community nurses descriptions of stress when caring in the home," Int. J. Palliat. Nurs., vol. 4, no. 1, 1998.

[17] A. S. Al-Aameri, "Source of job stress for nurses in public hospitals," Saudi Med. J., vol. 11, no. 24, pp. 1183-1187., 2003.

[18] W. F. Cascio, "Wither industrial and organizational psychology in a Changing world?," Am. Psychol., no. 50, pp. 928-939, 1995.

[19] K. B. Chan, G. Lai, Y. C. Ko, and K. W. Boey, "Work stress among six professional groups: the Singapore experience," Soc. Sci. Med., vol. 50, no. 10, pp. 1415-1432, 2000.

[20] G. Townley, "Long hours culture causing economy to suffer," Manag. Account., vol. 78, no. 6, pp. 3-5, 2000.

[21] T. A. Beehr, J. T. Walsh, and T. D. Taber, "Perceived situational moderators of the relationship between subjective role ambiguity and role strain," J. Appl. Psychol., vol. 61, pp. 35-40, 1976.

[22] C. L. Cordes and T. W. Dougherty, "A review and integration of research on job burnout," Acad. Manag. Rev., vol. 18 , pp. $621-656,1993$.

[23] C. L. Cooper, "Analysing Organisational Behaviour," in Stress in organizations, M. Smith, Ed. London: Macmillan Press, 1991

[24] S. Dyer and L. Quine, "Predictors of job satisfaction and burnout among the direct care staff of a community learning disability service," J. Appl. Res. Intellect. Disabil., vol. 11, no. 4, pp. 320-332, 1998.
[25] A. W. Ursprung, "Incidence and correlates of burnout in residential service settings," Rehabil. Couns. Bull., vol. 29, pp. 225-239, 1986.

[26] S. E. Jackson and R. S. Schuler, "A meta-analysis and conceptual critique of research on role ambiguity and role conflict in work settings," Organ. Behav. Hum. Decis. Process., vol. 36, pp. 16-78, 1985.

[27] P. Muchinsky, Psychology applied to work: An introduction to industrial and organizational psychology, Fifth. Pacific Grove, CA: Brookes Cole Publishers., 1997.

[28] T. K. and S. Pradeeswaran, "Effect of Occupational Stress on spiritual Quotient Among Executives," Int. J. Trade Financ., vol. 2, no. 4, pp. 28-29, 2011.

[29] C. L. Cooper, R. D. Cooper, and L. H. Eaker, Living with Stress. Penguin, 1998.

[30] A. P. Wolfgang, "The health professions stress inventory," Psychol. Rep., no. 62, pp. 220-222, 1988.

[31] A. K. Srivastav and A. P. Singh, Manual of the Occupational Stress Index. Varanasi: Banaras University, 1981.

[32] S. Anastasiadou and P. Thessaloniki, "Factorial validity evaluation of a measurement through principal components analysis and implicative statistical analysis," in Fifth Hellenic Conference of Pedagogy Company, 2006, pp. 341348 .

[33] R. Kayastha, V. Krishna Murthy, and P. R Adhikary, "Occupational Stress Among Executive Officers of Nepal: Empirical Study,” Int. journal's Res. J. Soc. Sci. Manag. RJSSM, vol. 2, no. 11, 2013.

[34] R. Kayastha, P. R Adhikary, and V. K Murthy, "Occupational stress among Managers: A Nepalese survey",', Acad. Res. Int., vol. 2, no. 3, pp. 585-590, 2013.

[35] R. Kayastha, V. K Murthy, and P. R Adhikary, "Occupational stress among higher secondary school teachers of Nepal: An Empirical study," Indian J. Mov. Educ. Exerc. Sci., vol. 2, no. 1, 2012.

[36] R. Kayastha, P. R Adhikary, and V. K Murthy, "An analytical study of Occupational stress on executive officers of Nepal,” Int. J. Acad. Res. Bus. Soc. Sci., vol. 2, no. 4, pp. $350-357,2012$.

[37] R. Kayastha, P. R Adhikary, and V. K Murthy, "Correlates of Occupational stress among executive officers of Nepal," Int. J. Res. Rev. Appl. Sci., vol. 12, no. 1, pp. 101-106, 2012.

[38] R. Kayastha, V. Krishnamurthy, and P. R Adhikary, "Identifying Occupational Stress Among Executive Officers in Governmental and Non-governmental Organizations of Nepal,” Int. J. Eval. Res. Educ., vol. 2, no. 2, 2013.

[39] R. Nargundkar, Marketing Research: Text and Cases. New Delhi: Tata McGraw Hill, 2002. 